\title{
ПОТЕНЦИАЛ МОДЕЛИ ОТКРЫТЫХ ИННОВАЦИЙ И ЕГО ИСПОЛЬЗОВАНИЕ
}

\author{
(c) 2020 Удальцова Наталья Леонидовна \\ кандидат экономических наук, доцент департамента Менеджмента и инноваций \\ Финансовый университет при Правительстве Российской Федерации, Россия, Москва \\ E-mail: udaltsova.nl@yandex.ru
}

\begin{abstract}
В статье рассматривается и исследуется модель «открытых инноваций». Автором выделены основные преимущества модели «открытых инноваций» и недостатки модели «закрытых инноваций». Выявлены основные риски модели «открытых инноваций» и проанализированы основные факторы, которые определили развитие и актуальность данной модели.
\end{abstract}

Ключевые слова: открытые инновации, инновации, технологическое развитие

\section{Введение}

На сегодняшний день, как в России, так и во всем мире, возрастает роль инноваций. Разработка и внедрение инноваций в текущую деятельность компаний характеризует эффективное конкурентоспособное развитие организации на рынке. Однако, как показывает практика, привычный способ управления инновационными проектами, предполагающий преимущественно использование собственных разработок организации, в современном мире во многих случаях становится малоэффективным: к примеру, собственные разработки компании не всегда способны реализовываться и быть успешными на рынке в силу ограниченных ресурсов организации, нехватки знаний в определенных областях и недостаточностью развитости в области НИОКР. Для повышения эффективности инновационной деятельности российских организаций решающее значение приобретает использование новых способов и методов управления инновациями. Один из самых актуальных и эффективных способов управления инновациями является концепция «открытых инноваций».

\section{Основная часть}

В 2003 году в своей книге «Открытые инновации профессор Калифорнийского университета (Беркли) Генри Чесбро сделал вывод, что не может быть так, чтобы все самые умные и талантливые люди работали на одну компанию, поэтому надо уметь работать с умными сотрудниками, как внутри, так и вне организации. Именно Генри Чесбро дал толчок к развитию новой модели управления инновациями в компаниях - модели «открытых инноваций». В своем исследовании Генри Чесбро утверждает, что организация при разработке новых технологий и продуктов, услуг не только использует собствен- ные внутрикорпоративные НИОКР, но и активно привлекает инновации и компетенции снаружи компании. Стоит отметить, что модель «открытых инноваций» не была изобретена Генри Чесбро, а данный факт был просто замечен при анализе крупных корпораций США с середины 1990-х годов.

В ходе своего исследования Генри Чесбро отметил, что инновации и разработки зарождаются в организации не в «закрытых» специализированных отделах, а внешний рынок способствует их поступлению. Кроме того, Генри Чесбро заметил, что больше половины инноваций в компании - это не ее собственные разработки, а приобретенные или заимствованные инновации с внешнего рынка и доведенные до конечного продукта.

Модель «открытых инноваций» предлагает множество преимуществ организациям, которые работают в рамках концепции глобального сотрудничества:

- снижение затрат на проведение НИОКР;

- потенциал для улучшения развития эффективности;

- подключение разных клиентов в начале процесса НИОКР;

- повышение точности маркетинговых исследований и ориентации на покупателя/клиента;

- потенциал синергизма между внешними и внутренними разработками;

- потенциал для вирусного маркетинга.

Однако модель «открытых инноваций» имеет множество рисков для компаний:

- риск раскрытия и потери важной личной информации;

- риск потерять преимущество перед конкурентами; 
- увеличенная сложность контроля и управления инновациями;

- изменение инновационных стратегий для выхода за пределы компании с целью максимизации отдачи от внешних инноваций.

Стоит отметить, что модель «закрытых инноваций» на протяжении долгого времени успешно функционировала на рынке и показывала неплохие результаты. Однако, в связи с быстрым развитием экономики, постоянно меняющимся рынком и другими фундаментальными факторами модель «закрытых инноваций» перестала оправдывать себя, что стало причиной возникновения новой модели - модели «открытых инноваций».

Факторы, обуславливающие переход к модели открытых инноваций следующие:

\section{1. Рост частного венчурного капитала.}

За последние десятки лет произошел значительный скачок в росте капитала, который направлялся на создание компаний, занимающихся коммерциализацией знаний, приходящих из внешних ресурсов. Именно такие стартапы стали серьезными конкурентами для крупных организаций, лидирующих в отрасли. Кроме того, благодаря зарождению концепции «открытых инноваций» именно эти крупные компаниилидеры в отрасли и инвестировали в те инновации и разработки, которые являлись опорой для создания продуктов и услуг стартапов.

На диаграмме выше видно скачкообразное увеличение венчурного финансирования, что характеризует факт передачи разработки инноваций компаний внешним организациям.

Согласно исследованию, изложенному в книге Генри Чесбро «Открытые инновации. Создание прибыльных технологий», появляются новые факторы, которые изживают старую модель модель «закрытых инноваций». Таким образом, происходит рост венчурного капитала, увеличивается мобильность работников и количество людей, получивших высшее образование. Все это способствует тому, что знания могут быть выведены на рынок разными путями. (рис. 2).

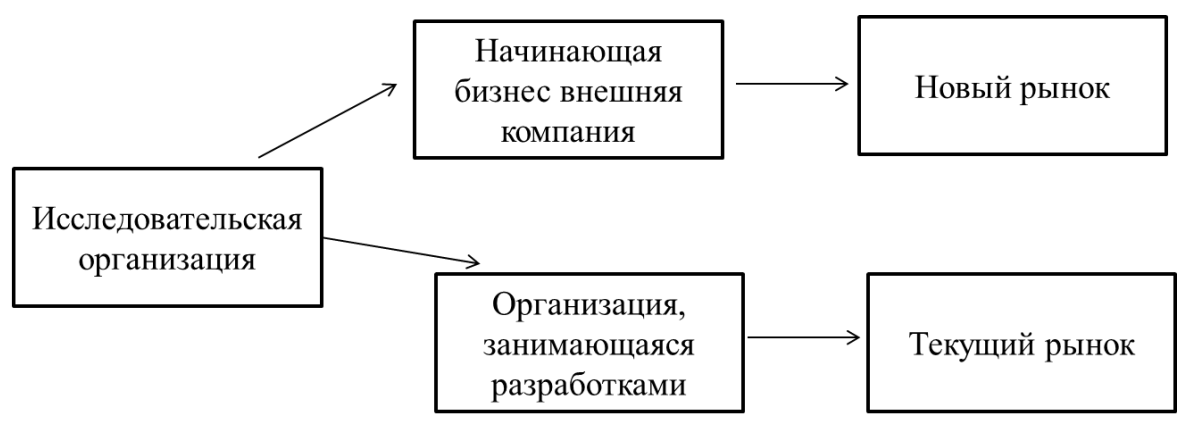

Puc. 2. Возможности реализации знаний в рамках модели открытой инновации (Источник: Г. Чесбро «Открытые инновации. Создание прибыльных технологий»: пер. с английского В.Н.Егорова - М.: Поколение, 2007.-91 с.)

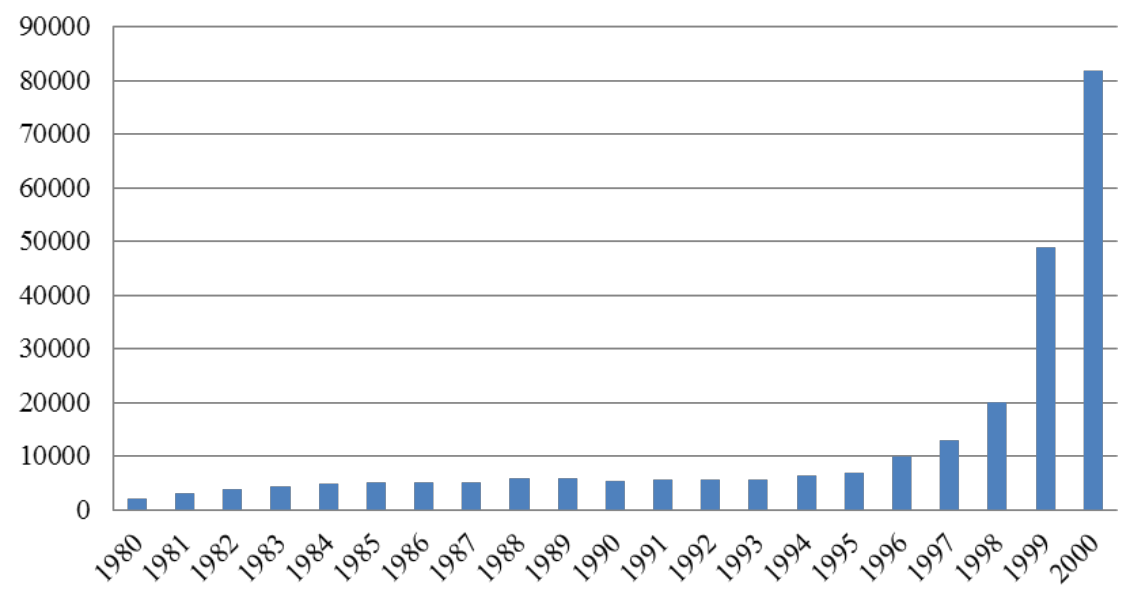

Puc. 1. Объем венчурного финансирования в США, млн. долларов США (Источник: Г. Чесбро «Открытые инновации. Создание прибыльных технологий»: пер. с английского В.Н.Егорова - М.: Поколение, 2007.-91с.) 
Согласно модели «закрытых инноваций», разработчики ожидали, пока определенное число специалистов сможет приступить к коммерциализации и продвижению созданных инноваций на внешний рынок. А сейчас идеи разработчиков имеют возможность реализоваться за пределами данной организации, другими словами, могут перейти в новую организацию уже на новом рынке.

\section{2. Рост конкуренции.}

Согласно наблюдениям Генри Чесбро, доля конкурентных рынков в США в 1939 году составляла 53\%, в 1959 году - 57\%, а в 1980 доля конкурентных рыков составила уже 78\% [2 с.93]. Согласно экономической теории, рост конкуренции ведет к развитию инноваций и, следовательно, способствует увеличению предложения новейших знаний на всем рынке. Другими словами, увеличивается число организаций, создающих инновации. В результате происходит необходимость увеличивать финансирование на НИОКР для устранения конкурентов. Для создания свеого лидерского положения компании начинают заострять внимание на небольшом количестве инновационных проектов. Компании начинают инвестировать менее в широкий спектр разработок, что приводит к инвестированию в только специальные отрасли. В итоге, все это увеличивает вероятность на успешность проекта и, соответственно, более быстрое получение конечного результата по сравнению с теми компаниями, которые имеют собственные большие исследовательские центры и распределяют свои инвестиции по множеству инвестиционных проектов и разработок. Однако, в силу того, что компании не всегда способны быть лидерами во всех отраслях и для поддержания конкурентного преимущества в отдельных областях, они вынуждены привлекать внешних партнеров или покупать инновации на внешнем рынке. Все вышеперечисленное стимулирует обмен знаниями и технологиями, таким образом, создается почва для появления новой модели -модели «открытых инноваций».

3. Увеличение роли ВУЗов как центров создания инноваций.

Уменьшение финансирования научных исследований университетов государством создало стимулы данным университетам к поиску новых источников финансирования своих разработок и исследований среди компаний. Это привело к том, что университеты стали хорошо разбираться в вопросах финансирования, поиска инвесторов, другими бизнес вопросами. Согласно данным книги Генри Чесбро «Открытые инновации. Создание прибыльных технологий» «В 1980-1990 гг. становится общепризнанным фактом, что ВУЗы и патентная система США являются одним из наиболее важных источников экономического роста США, определяющих ее конкурентоспособность в мире, что объясняется усиливающей значимостью НИОКР для инновационного развития США. Согласно мнению Генри Чесбро ВУЗы характеризуются им как «an engine for economic growth» («источники экономического роста»), а правовое оформление и коммерциализация результатов их исследований является единственным способом сохранения, привлечения, вознаграждения одаренных ученых, которые стремяться видеть, что их результаты исследований используются не просто так, а на благо общества. Знания, которые сейчас создаются в ВУЗах, стали более ориентированы на конкретные цели, которые возможно коммерциализировать. Подтверждение всему этому - увеличение патентов, получаемых ВУЗами: с 590 выданных патентов (0,8\% от общего числа выданных патентов) в 1985 г. до 3341 выданных патентов в 1999 г. (2,2\% от общего числа выданных патентов), причем 1509 патентов из 3341 выданных патентов ВУЗами в 1999 году (45\%), было получено 20 университетами [2 с.93].

\section{4. Увеличение степени распространенно-} сти знаний.

Успешное функционирование модели «закрытых инноваций» на рынке было связано с монополизацией отдельных крупных научноисследовательских центров на право владеть знаниями. По мере распространения знаний данное монопольное право стало ослабевать, что в дальнейшем привело к возникновению модели «открытых инноваций». Стоит отметить, именно данный факт являлся главным фактом при переходе от старой модели «закрытых инноваций» к новой - модели «открытых инноваций».

Таким образом, все вышеперечисленные факторы способствовали глобальным изменениям, включащим разрушение старой модели модели «закрытых инноваций» и добавления в цикл создания инноваций новые пункты (рис. 3).

На рисунке 3 представлен стартап в своем развитии. Развитие стартапа не входит в модель «закрытых инноваций», считатется, что средства, 


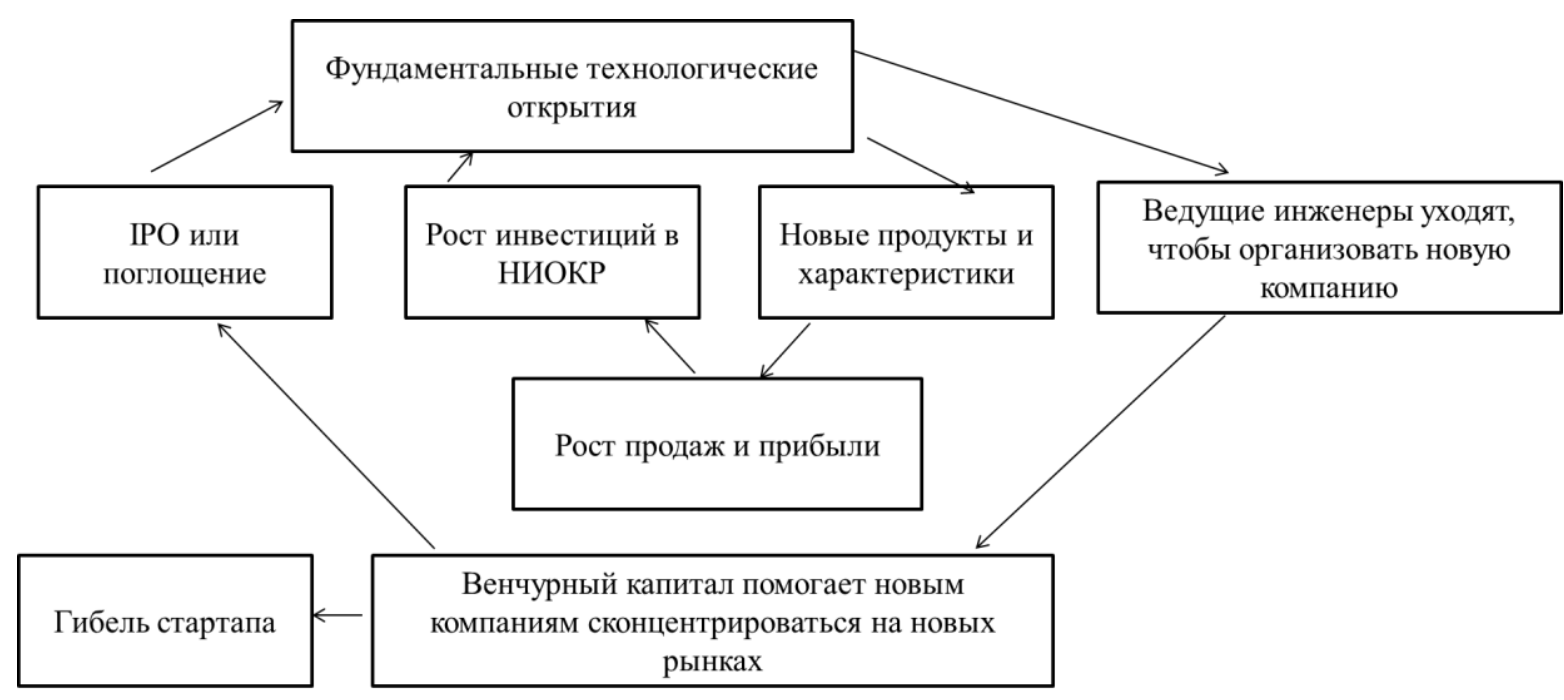

Puc. 3. Процесс создания инноваций в рамках функционирования модели «открытых инноваций» (Источник: Г.У.Чесборо «Логика «Открытых» инноваций: Новый подход к управлению интеллектуальной собственностью» // Российский журнал менеджмента - 2004. - № 4.- С. 71.)

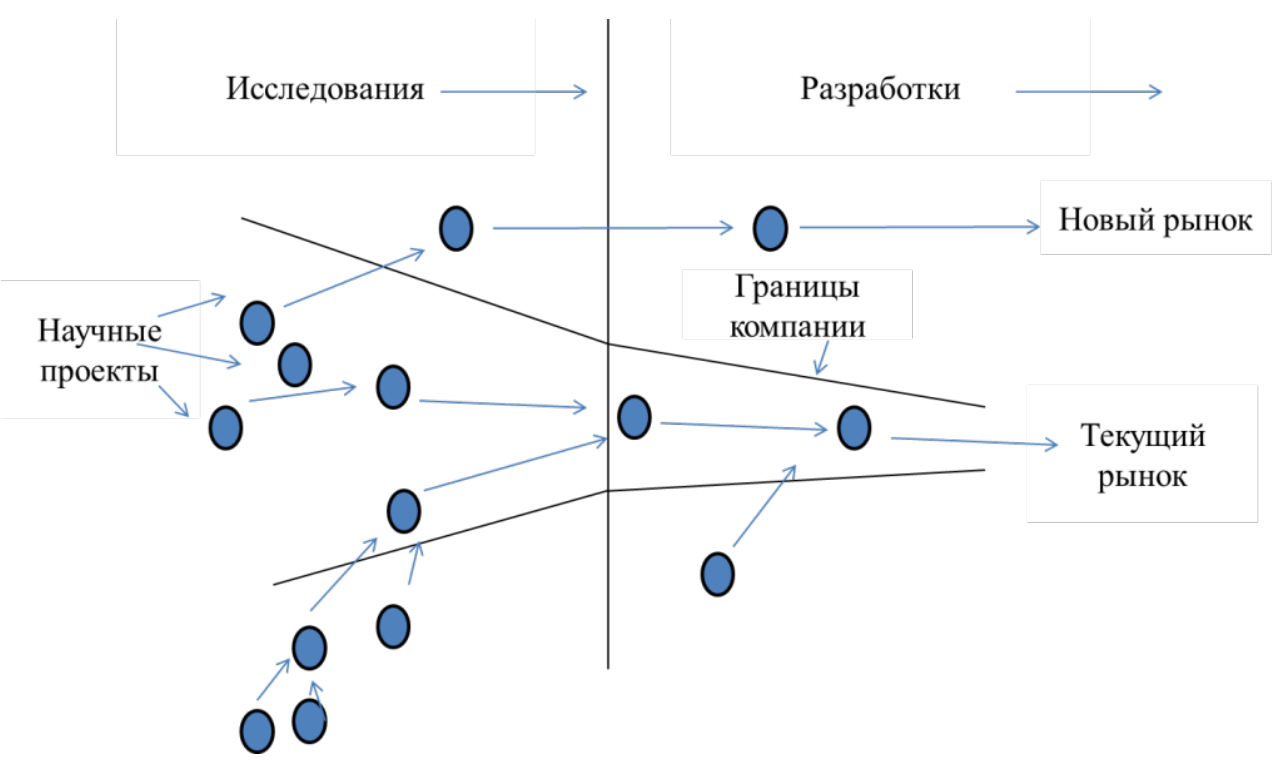

Puc. 4. Разработка продукции при функционировании модели «открытых инноваций»

(Источник: Открытые инновации [Электронный ресурс] // Avoimen Innovaation virallinen sivusto Suomessa. - 2006)

потраченные на инновации и разработки, могут не принести доход. Модель «закрытых инноваций» не может существовать из-за размытия прав собственности на результаты научной деятельности. Подробная информация изложена на рисунке ниже.

Модель «открытых инноваций» подразумевает использование специальных потоков знаний для увеличения внутренних инновационных процессов и расширения рыночного сег- мента для качественного использования инноваций. Модель «открытых инноваций» включает процесс, позволяющий исследованиям и разработкам быть в открытом доступе. Организация может использовать не только свои внутренние инновации при выходе на рынок, но также инновации и разработки, которые приобрела в сотрудничестве с внешними компаниями. Согласно теории «открытых инноваций» все знания широко распределены, и поэтому компании по- 
лучают максимум эффекта, когда приобретают (покупают или лицензируют) результаты изобретений других компаний и делятся (открывают для лицензируют и продают) своими инновациями.

Изобретение не является инновацией. Инновация, в первую очередь, это удовлетворение потребностей клиентов с помощью нового метода. Таким образом, изобретение всего лишь часть инновации. Существует такое выражение, что человек может быть изобретателем, но не быть новатором. Только новатор - человек, который смог изобрести новый способ удовлетворения потребностей клиентов, получает самую большую прибыль на рынке. Модель «открытых инноваций» позволяет использовать идеи, изобретения и технологии только в тех местах, где они действительно ценятся.

Существуют следующие недостатки закрытого процесса генерации инноваций в компаниях:

- Компания, функционирующая в рамках модели «закрытых инновации», тратит огромные ресурсы для решения проблем, связанных с внутренним рынком, хотя на внешнем рынке все доступно по сравнительно невысоким ценам;

- Большинство разработок компании не применяются на практике, и соответственно, не приносят прибыль;

- Часто компании «отметают» много проектов, которые на самом деле им ценны, просто неприменимы внутри организации или не соответствуют бизнес-моделям.

Использование модели «открытых инноваций» по сравнению с логикой модели «закрытых инноваций» требует особенного отношения к ситуационной модели. Кроме того, для модели «открытых инноваций» требуются специальные навыки и фокусировка внимания, а именно:

- для создания инновационного продукта, необходимо анализировать все этапы создания ценностей в отрасли (от поставщиков до конечных потребителей), так как инновационный продукт - это продукт, включающий все ключевые потребности клиентов, которые не реализовались;

- основная работа внутри модели «открытых инновациях» заключется, в первую очередь, в поиске идей, решений, технологий, которые будут использоваться для создания конечного продукта и удовлетворения потребностей кли- ентов. Внешний рынок содержит множество различных изобретений и технологий, поэтому изобрестать заново не требуется. Можно использовать, купить и лицензировать технологии и применять в своих целях и в различных сферах;

- модель «открытых инноваций» требует от новаторов быть коммуникабельным и, соответственно, иметь взаимовыгодное сотрудничество с большим числом самых разнообразных компаний и людей. Большое значение имеет выбор самых надежных партнеров, поставщиков, которые не подведут и смогут оценить идею, развить ее и довести до конечного продукта.

Экономисты С. Галлагер и Дж. Вест выделили несколько основных задач модели «открытых инноваций»: эффективное использование инноваций, мотивация, интеграция. Кроме того, экономисты определили основные стратегии модели «открытых инноваций».

1. Объединение процесса разработок и исследований в общий фонд.

2. Отдельные части инновационного продукта разрабатываются отдельными организациями.

3. Разработки широкого применения находятся в свободно продаже для использования и создания различных инновационных товаров.

4. Бюрократизм в крупных компаниях значительное уменьшается в области инновационной деятельности в силу различных процессов «открытых инноваций».

Знаменитый политик Г.Шварц отмечал, что для эффективного функционирования модели «открытых инноваций» для совместного проведения разработок и исследований потребуется создание различных партнерств. Партнерства позволят создать оптимальную бизнес-модель, снизить затраты на исследования и разработки, увеличить объемы выпуска и создать абсолютно новые рынки инновационного товара. Вначале пути организациям необходимо определить основные цели для бизнес-процесса в целом и также бизнес-цели для отдельного партнера; классифицировать возможности компании в области исследований и разработок; согласовывать компаниям, участвующих в инновационном процессе все бизнес-модели.

Согласно теории модели «открытых инноваций», данная модель не несет в себе смысл ликвидации и запрета на использование внутренних лабораторий организации, а подразумевает симбиоз использования внутренних и внешних 
источников получения знаний. Другими словами, организация не должна концентрироваться на самой себе в сфере разработок и инноваций и тем самым пропускать инновации, разрабатываемые вне компании. Используя модель «открытых инноваций» организация должна использовать в исследовании знания и опыт на внешнем рынке. Теперь исследовательская команда имеет новые обязанности и полномочия: кроме проведения собственных разработок и исследований, исследовательская деятельность теперь подразумевает под собой анализ, оценку и интеграцию внешних знаний. Также внутренние исследовательские группы компании должны заниматься созданием отсутствующих знаний в определенных отраслях, которых не существует ни внутри, ни извне. Компания также должна заниматься оценкой возможности получения дохода от знаний, которыми обладает организация, пользуясь внешними источниками получения знаний.

Стоит отметить, что защита прав на интеллектуальную собственность компании тоже является важным пунктом в условиях функционирования модели «открытых инноваций», также как и в условиях функционирования модели «закрытых инноваций». При этом, компании, использующие модель «открытых инноваций» иначе относятся к защите прав на интеллектуальную собственность. Такие компании понимают, что успешное ноу-хау на рынке скрыть от конкурентов будет невозможно, так как новая технология, услуга или продукт, пользующиеся огромным спросом, будет скопирована и распространена в текущих условиях (так например, в 2017 году «80\% программного обеспечения в России, установленного на персональные компьютеры, было нелицензионным, что в денежном эквиваленте составило около 2,3 млрд. долларов США от совокупного ущерба при использовании компьютерных пиратских программ» [9]). Более того, патент приобретается на метод его получения, а не на результат, а разработчики, которые при- думали новый способ получения такого результата, могут изменить методику таким способом, чтобы он не подпадал под патент, или создать новый метод. Поэтому организации, работающие с помощью модели «открытых инноваций», часто используют лицензирование для создания и расширения своих разработок. В итоге выигрывают оба игрока: компания, создающая ноу-хау, получает стабильную прибыль, а у конкурентов, соответственно нет необходимости нести дополнительные затраты на собственную разработку данного нового продукта. Согласно данному подходу, внутри компании появляется внутренняя конкуренция, которая мотивирует внутренние отделы. Компании, функционирующие по модели «открытых инноваций», поддерживают существование конкуренции подобного рода в небольших количествах. Внутренние отделы исследований и разработок будут работать быстрее и эффективнее для предоставления новой разработки в маркетинговый отдел в определенный момент, иначе они получат нужную разработку вне компании, а маркетинговые отделы, в свою очередь, будут больше работать над новым продуктом при наличии риска передачи разработки внешней компании. В итоге компания выигрывает, имея защиту от позднего выхода на внешний рынок.

\section{Заключение}

Уже с самого начала существования модель «открытых инноваций» стала привлекательна для небольших компаний. Вопрос заключался в том, смогут ли компании-гиганты использовать данную модель, ведь в своем арсенале они имеют большие научно-исследовательские центры, обладают огромным потенциалом персонала и большими финансовыми ресурсами. Главный и первый пример в истории использования модели «открытых инноваций» крупными компаниями - пример компании International Business Machines Corporation (IBM), доказавший, что и крупные компании могут интегрировать как свои, так и заимствованные инновации.

\section{Библиографический список}

1. Chesbrough H. W. Open Innovation: The New Imperative for Creating and Profiting from Technology.- Cambridge, MA: Harvard Business School Publishing, 2003

2. Чесбро Г. Открытые инновации. Создание прибыльных технологий: пер. с англ. В.Н.Егорова - М.: Поколение, 2007.

3. Васильцов В.С. Развитие рынка инноваций в хозяйственной системе России / В. С. Васильцов.- СПб.: Издво политехн. ун-та, 2017. 
4. Кудрявцева С.С., Шинкевич А.И. Применение логистического подхода в моделировании открытых инноваций._URL: http://euii-journal.ru

5. Денисов Д. И. Модель открытых инноваций. - URL: http://www.cfin.ru

6. Семенова Н.Н. Глобализация и открытые инновации.-URL: http://elibrary.ru

7. Балашов А.И., Рогова Е.М., Ткаченко Е. А. Инновационная активность российских предприятий: проблемы измерения и условия роста.-СПб.: Изд-во СПб. гос. политехн. ун-та, 2017.

8. Гросфелд T., Роландт Т. Логика открытых инноваций: создание стоимости путем объединения сетей и знаний // Форсайт. - 2016.

9. Денис Антонов «Уровень пиратства в России» - http://www.tadviser.ru 